\title{
Satellite data show Indian water stocks shrinking
}

Unsustainable water use in India is threatening agricultural production and raising the spectre of a major water crisis.

Matthew Rodell of NASA's Goddard Space Flight Center in Greenbelt, Maryland, and colleagues used data from the Gravity Recovery and Climate Experiment (GRACE) satellites - operated by NASA and the German Aerospace Center (DLR) - to determine how groundwater levels are changing in the Indian states of Rajasthan, Punjab and Haryana, which includes the national capital of New Delhi.

Their research, published online in Nature this week (M. Rodell et al. Nature doi:10.1038/ nature 08238 ; 2009), found gravity anomalies suggesting a net loss of 109 cubic kilometres of water - equivalent to a mass of 109 billion tonnes - from August 2002 to October 2008.
The amount lost is double the capacity of India's largest surface-water reservoir, the Upper Wainganga, and almost three times the capacity of Lake Mead in Nevada, the largest reservoir in the United States.

A second study using GRACE data, by scientists at the University of Colorado and the National Center for Atmospheric Research in Boulder, has found that the most intensively irrigated areas in northern India, are losing groundwater at an overall rate of 54 cubic kilometres per year, consistent with Rodell's results (V. M. Tiwari et al. Geophys. Res. Lett. doi:10.1029/2009GL039401; in the press).

Groundwater depletion in northwest India is a known problem, but Rodell's data suggest that the loss rate is around $20 \%$ higher than the Indian authorities have previously estimated.

Rodell notes that rainfall during the study period was close to the long-term climatic mean, and says that the observed groundwater depletion is unlikely to be the result of unusual dryness or variability.

The regions of Rajasthan, Punjab and Haryana have a combined population of 114 million people, and receive an average of 500 millimetres of rainfall per year just slightly less than that of London - but with pronounced seasonal and regional differences. Although less than a third of agricultural land there is irrigated, crop irrigation accounts for up to $95 \%$ of groundwater consumption. "If farmers could shift away from water-intensive crops, such as rice, and implement more efficient irrigation methods, that would help," says Rodell.

Meanwhile, the Indian government is looking into framing regulations to reduce groundwater consumption. "Hopefully," says Rodell, "our research will give them the evidence they need to carry through."

Quirin Schiermeier 